\title{
Predicting disclosure and help-seeking in university students with psychosocial problems based on stigma and attitudes towards disclosure and help-seeking
}

\author{
Jolien M Dopmeijer ${ }^{1,5 *}$, Jannet M de Jonge ${ }^{2}$, Tommy LS Visscher ${ }^{3}$, Rob HLM Bovens ${ }^{4}$ and Reinout W Wiers ${ }^{5}$ \\ ${ }^{1}$ Department of Health and Wellbeing, Windesheim University of Applied Sciences, Zwolle, the Netherlands \\ ${ }^{2}$ ACHIEVE, Centre of Applied Research, Faculty of Health, Amsterdam University of Applied Sciences, Amsterdam, the Netherlands \\ ${ }^{3}$ Department of Health and Wellbeing, Research Centre for Healthy Society, Windesheim University of Applied Sciences, Zwolle, the Netherlands \\ ${ }^{4}$ Tranzo, Scientific Center for Care and Wellbeing, Tilburg University, Tilburg, The Netherlands \\ ${ }^{5}$ Addiction Development and Psychopathology (ADAPT-)lab, Department of Psychology, and Centre for Urban Mental Health, University of Amsterdam, \\ Amsterdam, the Netherlands
}

\begin{abstract}
Despite high prevalence of mental health problems among university students, there's a gap between the need for help and the actual treatment received. This study investigated disclosure on distress and hazardous alcohol use and help-seeking behavior in a sample of 1,791 students of a Dutch university of applied sciences. Students' perceived public and personal stigma, and attitudes towards disclosure and help-seeking were assessed as possible predictors of disclosure and help-seeking behavior. Results of the analysis of variance and logistic regression analysis indicated that perceived public and personal stigma did not predict disclosure and helpseeking behavior, but that attitudes towards disclosure and help-seeking did. Students with both distress and hazardous alcohol use have the least tendency to disclose their problems to family, friends or classmates, but at the same time they do tend to seek help. Disclosure and seeking help for mental health challenges are health promoting competencies that seem to need more attention in university students. Although further research needs to validate these findings, it is recommended to promote disclosure and help-seeking among students by investing in mental health literacy programs, to educate students about mental health issues, raise awareness on available mental health services and their potential benefits.
\end{abstract}

\section{Introduction}

University students are a vulnerable population with high risks for development of mental health problems and disorders [1]. They are in the midst of young adulthood, which is known to be a critical period in which $75 \%$ of mental health problems have their first onset before the age of 24 [2]. Although university may be an exciting period for some students, for others it is a difficult time. For a number of them, pre-existing psychosocial problems may persist or worsen during the course of their studies, while others develop psychosocial problems for the first time [1,3-4]. Severe distress, burnout, loneliness, problematic alcohol use, illicit substance use, anxiety, depression and even suicidal ideation are some of the mental health issues that have been documented as highly prevalent in university students over the past years $[1,4-12]$. There is evidence that these mental health issues can have a serious impact on academic performance and may subsequently lead to academic delay and dropout $[3,13]$.

The high prevalence of distress and mental health disorders among students would be less concerning if these students were receiving appropriate treatment [8]. However, research shows that there is a gap between the need for mental health treatment and actual receipt of treatment, despite the fact that most students have access to mental health services on campus and insurance to cover these services [14]. Without appropriate treatment for mental health problems, students face a range of potentially serious and lasting consequences, including dropping out, difficulties with relationships and future mental illness
[2,14-15]. Students with mental health problems appear to experience barriers for the use of mental health services which affect their helpseeking behavior [16]. Although students' problems may pass, when they don't, many students suffer in silence, don't seek help and go unnoticed, or seek help in a later stage when their problems already have become more severe. This makes it difficult to offer assistance, while by increasing helping-seeking behaviors, student mental health and subsequently their academic performance, could be considerably improved. This makes it important to better understand what the barriers are that students experience regarding help-seeking for mental problems.

Help-seeking behavior is shaped by intention, which, in turn, is influenced by attitudes [17]. There are several frameworks with explaining theories on help-seeking behavior for mental health. One of them is the Health Belief Model, which emphasizes the individual approach to explain perceived need and help-seeking [18]. The model is based on the theory that one's willingness to change health behaviors

*Correspondence to: Jolien M Dopmeijer, Department of Health and Wellbeing, Windesheim University of Applied Sciences, Zwolle, Netherlands, E-mail: jm.dopmeijer@windesheim.nl

Key words: disclosure, help-seeking behavior, mental health, stigma, university students

Received: May 29, 2020; Accepted: June 16, 2020; Published: June 19, 2020 
and seek help, is primarily due to 1) perceived susceptibility: the belief that one's behavior concerns a risk; 2) perceived severity: the extent to which one considers the consequences of their behavior to be serious enough to avoid these consequences; 3 ) perceived benefits: the belief that changing behaviors will improve one's problem; and 4) perceived barriers, like social difficulties or stigma [18]. Consistent with the Health Belief Model, many studies have focused on individuals' attitudes and beliefs about mental illness and treatment to understand the individual students' decision to (not) seek help for his or her mental health problems. These studies conclude that negative attitudes and beliefs are significant barriers to help-seeking, in which two forms of stigma are distinguished: perceived public stigma (negative attitudes toward oneself) and personal stigma (own negative attitudes to help-seeking) [19]. Perceived public stigma refers to an individual's perception of public stigma: negative stereotypes and prejudice about mental illness (such as: 'people with mental illness are weak') [20]. Students' own view of people who use mental health treatment, which may differ from how students would view themselves in the same situation (i.e., self-stigma), is referred to as personal stigma [19].

Help-seeking facilitating factors which encourage someone to seek help for their distressing problems include being willing to self-disclose personally distressing information to others [21]. Students' intentions to seek help are likely related to the fear of disclosing personal information to others and not fitting in anymore. Having a sense of commitment and fitting in with their peer group is very important to young adults in their developmental stage [22,23]. Therefore, students with mental health problems are confronted with the dilemma of disclosure. On the one hand, disclosure might lead to stigmatization with a negative impact for conformity, but on the other hand disclosure may lead to social support provision [24]. Corrigan, et al. state that the desire for disclosure is directly associated with identity, i.e., whether students view themselves as people with mental health issues. Corrigan, et al. also state that experiencing barriers to disclose mental health problems are a result of shame of one's issues. Additionally [6], suggest disclosure may be a key factor in decreasing stigma: the less people endorse stereotypes about mental health issues, the more likely one will disclose. Women endorse stigma less than men and it is expected that women are more likely to disclose than men [6].

The aforementioned studies show that students seem to come across barriers in disclosing mental health issues and seeking help. Stigma and attitudes towards disclosure and help-seeking behavior are seen as a key-factors that contribute to decisions concerning disclosure and help-seeking or not. It is likely that perceived public and personal stigma also form barriers for disclosure and help seeking in students. Therefore, it is important to determine if students indeed experience stigma as a barrier for disclosure and help seeking, what their attitude towards disclosure and help seeking is, and to what extent they actually disclose and seek help. The main aim of the present study was to determine if stigma and attitudes towards disclosure and help-seeking behavior predicted actual disclosure and help seeking among students.

\section{Methods}

\section{Procedure and participants}

Cross-sectional data were used from the $6^{\text {th }}$ wave of the Study Environment, Health and Study Success online survey, carried out between December 2018 and February 2019 in a large university of applied sciences in the Netherlands. All fulltime students were invited by email $(n=1,791)$. They were informed upfront about the objective and procedure of the study and participated voluntarily and anonymously. The consent of the participants was obtained by virtue of survey completion.

\section{Measures}

Outcomes: Our dependent variables of main interest were binary. We assessed actual informal disclosure (within one's own social contacts and networks) with a single item: 'Did you disclose your mental health problems to family, friends and/or classmates?' (no=0; yes $=1$ ). We also included a single item on actual help seeking from professional sources: 'Did you seek help with a mental health professional or a student counselor within or outside the university?' (no=0; yes=1). Note that disclosure and help-seeking outcomes were only assessed among students who indicated that they suffered from psychosocial problems on a separate question in the survey, apart from the screeners for distress and alcohol use $(n=708)$, because the precondition for disclosure of mental health problems and help-seeking behavior is that one is aware of and suffers from such problems.

Psychosocial problems: Distress (symptoms of anxiety and depression) was assessed with the Dutch version of the Kessler-6 psychological distress scale, which is the brief 6 item version of the Kessler-10 scale, consisting of ten items [25]. The questions assessed how frequently one experienced the following six symptoms: felt nervous, hopeless, restless or fidgety, worthless, depressed and felt that everything was an effort. Responses ranged on a 5-point Likert scale from 1 (almost never) to 5 (almost always) and were summed to yield a K6 score between 1 and 30, with higher scores indicating higher distress and a greater tendency towards mental illness, i.e., anxiety or depression. Alcohol use was assessed with the Dutch version of the Alcohol Use Disorders Identification Test-Consumption (AUDIT-C) [26], which is the brief three item version of the Alcohol Use Disorders Identification Test (AUDIT). The questions assessed frequency of drinking, typical number of drinks consumed on a drinking day, and frequency of binge drinking. Responses to each item were scored from 0 to 4 and were summed to yield a score between 0 and 12, with higher scores indicating hazardous drinking. The AUDIT-C appeared valid to identifying hazardous drinking students, e.g. at-risk students in our previous study [12]. Being at risk for hazardous alcohol use in the present study was determined based on this previous study, in which we suggested specific cut-offs of 7 for female students and 8 for male students.

\section{Demographics}

Age and gender: These were obtained from data of the Student Administration of the university. Age was expressed in years, and gender was coded dichotomously ( $1=$ male, $2=$ female $)$.

Predictors: Our predictors were divided into two categories: attitudes (attitudes towards disclosure and attitudes towards helpseeking behavior) and stigma (Perceived public stigma and personal stigma). Attitudes towards disclosure was assessed with the Mental Illness Disclosure Scale [24]. This is a 12 item scale measuring the intention to disclose mental health problems on a 7 point Likert Scale $(0=$ totally disagree to $6=$ totally agree). Higher average scale scores indicated greater intentions to disclose mental health problems.

Attitude towards help-seeking behavior: It was assessed with the Inventory of Attitudes Toward Seeking Mental Health Services (IASMHS), a 24 item scale consisting of 3 subscales: psychological openness (the degree to which one is open to acknowledging the presence of a psychological problem and to seek professional care for such a problem), help-seeking propensity (one's intention and perceived ability to seek help for psychological problems) and indifference to 

help-seeking

stigma (how concerned one would feel were significant others to discover that they were receiving psychological care) [27]. Each scale included 8 questions and answers were measured on a 5 point Likert Scale $(0=$ totally disagree to $4=$ totally agree), giving a range of each subscale from $0-32$. The total IASMHS gives a range from $0-96$, with higher scores indicating greater intention to seek help.

\section{Perceived public stigma}

It was assessed using an adaptation of the DiscriminationDevaluation (D-D) Scale developed by Link, after the example of [28]. In the D-D scale the extent to which one agrees on 12 items on public stigma that begin with "Most people believe..." or "Most people think..." or "Most people would.." was measured on a 5 point Likert scale: totally agree $(=0)$ to totally disagree $(=4)[29,30]$. The original D-D scale refers to 'mental patient' or a 'former mental patient' or 'a person who has been hospitalized for mental illness'. Because we wanted to assess perceived public stigma regarding a broader concept of mental health treatment than only institutional treatment for severe mental illness, we adapted the wording to 'a person who has received mental health treatment', after the example of Eisenberg and colleagues. Average scale scores were computed, with higher scores indicating higher perceived public stigma.

Personal stigma, students' own stigmatizing attitudes about mental health treatment, was also assessed after the example of [28]. Three items of the D-D scale were adapted replacing 'most people' by 'I'. These three items referred to a negative attitude (...'would think less of someone...'), an accepting behavior (...'would accept as a close friend...'), and an accepting attitude (...'think someone is just as trustworthy...'). These three items were measured on a 5 point Likert scale ranging from totally agree $(=0)$ to totally disagree $(=4)$. The average scale score was computed, with higher scores indicating higher personal stigma.

\section{Statistical analysis}

Sociodemographic characteristics and descriptive values for all variables were calculated using IBM SPSS Statistics, version 25 [31]. Normality tests were performed and revealed a normal distribution of the data. Intercorrelations were calculated for all predictors to detect multicollinearity, which occurs when variables are over correlated. This could cause problems in validation, interpretation, and analysis of the model. In the present study, all correlations were below .40, indicating that our predictors were not strongly correlated, and collinearity should not be an issue [32,33]. Furthermore, we tested for unadjusted differences in mean levels for attitudes towards disclosure and help-seeking behavior, and public and personal stigma across subgroups using t-tests. Additionally, multivariate analysis of variance (MANOVA) was used to test the significance of differences between the levels of these attitudes and stigma of four subgroups with or without one or more symptoms of distress and alcohol use. In case of significant effect(s), the MANOVA was followed up by discriminant analysis to determine the relative contribution of the different variables to the multivariate effect (which is the correct follow-up, instead of the often used ANOVA follow-up, see [34]. Finally, since our outcomes are binary, a logistic regression was conducted with the dependent variables disclosure and help-seeking behavior. The predictors used in each of these logistic regressions were attitude towards disclosure, attitude towards help-seeking behavior, and perceived public stigma and personal stigma. As disclosure and help-seeking are related to experienced mental health problems, we controlled for the most common mental health problems, i.e., distress and hazardous alcohol use, as well as for age and gender.

\section{Results}

Sample characteristics are shown in Table 1. The sample had a mean age of 21.5 years old ( $\mathrm{SD}=3.8$ ) and almost $60 \%$ was female. More than half of the students in our sample experienced psychological distress (56.3\%), i.e., symptoms of anxiety and depression, and $20.9 \%$ of our sample were at risk for hazardous alcohol use. Problems were disclosed by $32.8 \%$ of the students. Half of the students with distress and/or hazardous alcohol use sought help for their problems (49\%) and the other half did not (51\%).

Before conducting analyses of variance and logistic regression analyses, descriptive statistics and intercorrelations were calculated for all predictors. Table 2 summarizes means, standard deviations and intercorrelations of measures of perceived public and personal stigma, and attitudes towards disclosure and help seeking. Furthermore, Table 2 shows medium to low levels of both perceived public stigma $(M=1.8, S D=0.3)$ and personal stigma $(M=1.6, S D=0.4)$. This indicates that although students hold slightly more perceptions of collectively held prejudices regarding people with mental health issues than that they hold prejudices themselves. Overall they experience little stigma. Additionally, a low to moderate mean score was also found on both the attitude towards disclosure scale $(M=2.8, S D=1.1)$ and the attitude towards help seeking behavior scale $(M=1.8, S D=0.3)$. This suggests reluctance among students to disclose mental health problems to their family, friends or classmates, and not a favorable attitude to seek help among professionals within or outside of university.

As shown in Table 3, there were significant differences regarding attitude towards disclosure in scores for students with distress $(M=2.66, S D=1.13)$ and students without distress $(M=3.03, S D=1.02)$; $t(1789)=7.131, p<0.001$, which suggests that students with distress tend to disclose less than students without distress. Regarding attitude towards help-seeking behavior significant differences were found in the scores for men $(M=1.86, S D=0.31)$ and women $(M=1.80, S D=0.28)$;

Table 1. Sample characteristics $(\mathrm{N}=1,791)$

\begin{tabular}{|c|c|}
\hline & \% Participants \\
\hline Variable & $(N=1,791)$ \\
\hline \multicolumn{2}{|l|}{ Gender } \\
\hline Male & 41.3 \\
\hline Female & 58.7 \\
\hline Age (mean, SD) & $21.5(3.8)$ \\
\hline \multicolumn{2}{|l|}{ Living situation } \\
\hline Living independently & 27 \\
\hline Living with parents & 73 \\
\hline \multicolumn{2}{|l|}{ Year of study } \\
\hline $1^{\text {st }}$ & 29.8 \\
\hline $2^{\text {nd }}$ & 20.3 \\
\hline $3^{\text {rd }}$ & 22.3 \\
\hline $4^{\text {th }}$ & 18 \\
\hline $5^{\text {th }}$ or higher & 9.6 \\
\hline \multicolumn{2}{|l|}{ Psychological distress (K6) } \\
\hline No & 43.7 \\
\hline Yes & 56.3 \\
\hline \multicolumn{2}{|c|}{ Hazardous alcohol use (AUDIT-C) } \\
\hline Not at risk & 78.1 \\
\hline At risk & 20.9 \\
\hline \multicolumn{2}{|c|}{ Distress and hazardous alcohol use combined } \\
\hline No distress, no alcohol risk & 33.3 \\
\hline Distress, no alcohol risk & 44.8 \\
\hline No distress, alcohol risk & 10.4 \\
\hline Distress and alcohol risk & 11.5 \\
\hline
\end{tabular}


Dopmeijer JM (2020) Predicting disclosure and help-seeking in university students with psychosocial problems based on stigma and attitudes towards disclosure and help-seeking

Table 2. Means (M), Standard Deviations (SD), and Intercorrelations of Perceived Public Stigma, Personal Stigma, Attitude towards Disclosure and Help-Seeking Behavior (N=1,791)

\begin{tabular}{|c|c|c|c|c|c|c|}
\hline & $M$ & $S D$ & 1 & 2 & 3 & 4 \\
\hline 1. Perceived Public Stigma & 1.8 & 0.3 & - & 0 & 0.04 & 0.02 \\
\hline 2. Personal Stigma & 1.6 & 0.4 & & - & -0.04 & 0.07 \\
\hline 3. Attitude Disclosure & 2.8 & 1.1 & & & - & -0.4 \\
\hline 4. Attitude Help-Seeking Behavior & 1.8 & 0.3 & & & & - \\
\hline
\end{tabular}

Table 3. Results of the Independent Samples t-Test $(\mathrm{N}=1,791)$

\begin{tabular}{|c|c|c|c|c|c|c|}
\hline \multirow[b]{2}{*}{ Variable (scale range) } & \multicolumn{2}{|c|}{ Gender (Mean, $S D$ ) } & \multicolumn{2}{|c|}{ Distress (Mean, $S D$ ) } & \multicolumn{2}{|c|}{ Alcohol risk (Mean, $S D$ ) } \\
\hline & $\begin{array}{c}\text { Male } \\
(\mathrm{n}=740)\end{array}$ & $\begin{array}{l}\text { Female } \\
(\mathrm{n}=1051)\end{array}$ & $\begin{array}{l}\text { No distress } \\
(\mathrm{n}=783)\end{array}$ & $\begin{array}{l}\text { Distress } \\
(\mathrm{n}=1008)\end{array}$ & $\begin{array}{l}\text { No alcohol risk } \\
\quad(\mathrm{n}=1398)\end{array}$ & $\begin{array}{l}\text { Alcohol risk } \\
(\mathrm{n}=393)\end{array}$ \\
\hline Attitude disclosure (0-4) & $2.85(1.07)$ & $2.80(1.12)$ & $3.03(1.02)^{*}$ & $2.66(1.13)^{*}$ & $2.83(1.08)$ & $2.77(1.16)$ \\
\hline Attitude help-seeking (0-6) & $1.86(0.31)^{*}$ & $1.80(0.28)^{*}$ & $1.79(0.28)^{*}$ & $1.86(0.31)^{*}$ & $1.82(0.29)^{*}$ & $1.86(0.33)^{*}$ \\
\hline Perceived public stigma (0-4) & $1.83(0.35)$ & $1.81(0.33)$ & $1.82(0.33)$ & $1.81(0.35)$ & $1.83(0.33)^{*}$ & $1.78(0.37)^{*}$ \\
\hline Personal stigma (0-4) & $1.66(0.44)^{*}$ & $1.62(0.41)^{*}$ & $1.65(0.42)$ & $1.63(0.43)$ & $1.64(0.42)$ & $1.63(0.44)$ \\
\hline
\end{tabular}

$t(1789)=4.322, p<0.001$, and in scores for students with distress $(M=1.86, S D=0.31)$ and without distress $(M=1.79, S D=0.28) ; t(1789)=$ $-4.821, p<0.001$ and finally, in scores for students with an alcohol risk $(M=1.86, S D=0.33)$ and without an alcohol risk $(M=1.82, S D=0.29)$; $t(1789)=-2.455, p<0.05$. These findings indicate that male students, students with distress and students at risk for hazardous alcohol use have a more positive attitude toward help-seeking. Furthermore, the perceived public stigma of students with an alcohol risk $(M=1.78$, $S D=0.37)$ and without an alcohol risk $(M=1.83, S D=0.33)$ were found to be significantly different; $t(1789)=2.987, p<0.05$, indicating that students at risk for hazardous alcohol use experience more public stigma regarding mental health problems than students who are not at risk for hazardous alcohol use. Finally, there were significant differences regarding personal stigma in men $(M=1.66, S D=0.44)$ and women $(M=1.62, S D=0.41) ; t(1789)=2.047, p<0.05$. This result suggests that male students experience greater personal stigma than women.

Additionally, a multivariate analysis of variance (MANOVA) was performed to investigate effects of symptoms of distress and hazardous alcohol use on attitudes towards disclosure and help-seeking behavior, and perceived public and personal stigma. A significant main effect was found for distress (Wilks' $\Lambda=.968, \mathrm{~F}_{4,1786}=14.615, p<0.01, \eta^{2}=0.03$ ), and for hazardous alcohol use (Wilks' $\Lambda=.991, \mathrm{~F}_{4,1786}=4.120, p<0.01$, $\eta^{2}=0.08$ ). In addition, significant interactions between distress and hazardous alcohol use were found (Wilks' $\Lambda=.953, \mathrm{~F}_{4,1786}=7.204, p<$ $0.01, \eta^{2}=0.02$ ). With the interaction effect being significant, the means and standard deviations of the subgroups are presented in Table 4.

In order to determine the relative contribution of the variables to the multivariate effects described above, we performed a series of discriminant analyses [34]. For the first multivariate effect (distress) the most strongly contributing variables were attitude towards disclosure and attitude towards help-seeking behavior. The relative contributions to the multivariate difference between low and high distress were (in descending order, with structure coefficients in parentheses): attitude towards disclosure (0.93), attitude towards help-seeking behavior $(-0.63)$, perceived public stigma (0.15) and personal stigma (0.11). These results indicate that students with high distress have the least tendency to disclose their problems to family, friends or classmates, but at the same time they show the most positive attitude towards seeking help with mental health care professionals.

For the second multivariate effect (hazardous alcohol use) the most strongly contributing variables were perceived public stigma, attitude towards help-seeking behavior and attitude towards disclosure. The relative contributions to the multivariate difference between non- hazardous and hazardous alcohol use were: perceived public stigma (0.77), attitude towards help-seeking behavior ( -0.63$)$, attitude towards disclosure (0.28) and personal stigma (0.15). These results indicate that students with hazardous alcohol use tend to disclose, but have little tendency to seek help.

In the discriminant function of the interaction (including the four groups in Table 4), the first function explained $82.5 \%$ of the variance, followed by a second function that explained $16.1 \%$ of the variance. The most strongly contributing variables in the first function were attitude towards disclosure (0.93) and attitude towards help-seeking behavior (-0.63). In the second function perceived public stigma was the most important contributing factor $(-0.73)$. These interaction results indicate that students with high distress and hazardous alcohol use have the least tendency to disclose their problems to family, friends or classmates, but at the same time they show the most positive attitude towards seeking help with mental health care professionals and the least perceived public stigma.

\section{Predictive analyses using logistic regression}

The last step involved using stepwise logistic regression analysis to determine predictors of actual disclosure and help-seeking behavior. Details results of the stepwise binary logistic regression analyses are shown in Table 5.

\section{Predicting disclosure}

Attitudes toward disclosure and attitudes toward help-seeking behavior significantly predicted disclosure. The value of the odds of attitude towards disclosure indicates that as one's tendency to disclose increases, the odds of actual disclosure increases by a factor of 1.766 . The student's attitude towards help-seeking behavior also contributes to the prediction of disclosure; as a students' tendency to seek help decreases, the odds of disclosure of mental health problems decreases by a factor of .417 . The logistic regression model for disclosure did not improve by adding age and gender, distress and alcohol risk, and perceived public stigma and personal stigma.

\section{Predicting help-seeking behavior}

Age and attitude towards disclosure significantly predicted help seeking. Likelihood to seeking help increased by a factor of 1.076 per year of age. Further, the value of the odds of attitude towards disclosure indicates that, as one's tendency to disclose increases, the odds of actual help seeking increases by a factor of 1.466. Gender, distress and alcohol risk, perceived public stigma, and perceived public stigma and personal stigma, did not predict help seeking significantly. 
Dopmeijer JM (2020) Predicting disclosure and help-seeking in university students with psychosocial problems based on stigma and attitudes towards disclosure and help-seeking

Table 4. Results of the MANOVA analysis $(\mathrm{N}=1,791)$

\begin{tabular}{|c|c|c|c|c|c|}
\hline & \multicolumn{4}{|c|}{ Subgroup } & \multirow[b]{2}{*}{$\begin{array}{c}\text { Total } \\
(\mathrm{N}=1,791)\end{array}$} \\
\hline & $\begin{array}{l}\text { No distress, } \\
\text { no alcohol risk } \\
(\mathrm{N}=\mathbf{5 9 6})\end{array}$ & $\begin{array}{l}\text { Distress, } \\
\text { no alcohol risk } \\
(\mathrm{N}=\mathbf{8 0 2})\end{array}$ & $\begin{array}{l}\text { No distress, } \\
\text { alcohol risk } \\
(\mathrm{N}=187)\end{array}$ & $\begin{array}{l}\text { Distress and } \\
\text { alcohol risk } \\
(\mathrm{N}=206)\end{array}$ & \\
\hline Predictor (scale range) & Mean $(S D)$ & Mean $(S D)$ & Mean $(S D)$ & Mean $(S D)$ & Mean $(S D)$ \\
\hline Attitude disclosure (0-4) & $3.00(0.28)$ & $2.71(1.11)$ & $3.13(1.04)$ & $2.44(1.18)$ & $2.82(1.10)$ \\
\hline Attitude help-seeking (0-6) & $1.78(0.28)$ & $1.84(0.29)$ & $1.81(0.29)$ & $1.90(0.36)$ & $1.83(0.30)$ \\
\hline Perceived public stigma (0-4) & $1.84(0.32)$ & $1.82(0.34)$ & $1.78(0.36)$ & $1.77(0.39)$ & $1.82(0.34)$ \\
\hline Personal stigma (0-4) & $1.66(0.42)$ & $1.63(0.42)$ & $1.63(0.40)$ & $1.62(0.47)$ & $1.64(0.43)$ \\
\hline
\end{tabular}

Table 5. Logistic regression analyses for disclosure and help-seeking behavior $(\mathrm{N}=708)$

\begin{tabular}{|c|c|c|c|c|c|}
\hline \multicolumn{6}{|l|}{ Disclosure } \\
\hline Variable & B & $\begin{array}{l}\text { Standard } \\
\text { Error }\end{array}$ & $\begin{array}{l}\text { Odds } \\
\text { Ratio }\end{array}$ & $95 \% \mathrm{CI}$ & $p$-value \\
\hline Constant & .780 & 1.448 & 2.182 & - & .590 \\
\hline \multicolumn{6}{|l|}{ Demographics } \\
\hline Age & .069 & .038 & 1.071 & {$[.995-1.153]$} & .067 \\
\hline Gender & .364 & .222 & 1.438 & {$[.930-2.225]$} & .102 \\
\hline \multicolumn{6}{|l|}{ Psychosocial problems } \\
\hline Distress & -.244 & .370 & .783 & {$[.379-1.618]$} & .510 \\
\hline Alcohol risk & -.255 & .247 & .775 & {$[.478-1.257]$} & .301 \\
\hline \multicolumn{6}{|l|}{ Attitude } \\
\hline Attitude disclosure & .569 & .109 & 1.766 & {$[1.426-2.186]$} & $<.001 *$ \\
\hline Attitude help-seeking & -.876 & .382 & .417 & {$[.197-.881]$} & $.022 *$ \\
\hline \multicolumn{6}{|l|}{ Stigma } \\
\hline Perceived public stigma & -.065 & .316 & .937 & {$[.505-1.740]$} & .837 \\
\hline Personal stigma & -.344 & .257 & .709 & {$[.428-1.173]$} & .181 \\
\hline \multicolumn{6}{|c|}{$\begin{array}{l}\text { Model Likelihood Nagelkerke } \mathrm{R}^{2}=.168 \\
\text { Hosmer \& Lemeshow Goodness-of-fit Test: } \mathrm{X}^{2}=7.02, d f=8, p=.53\end{array}$} \\
\hline \multicolumn{6}{|l|}{ Help-seeking behavior } \\
\hline Variable & B & $\begin{array}{l}\text { Standard } \\
\text { Error }\end{array}$ & $\begin{array}{l}\text { Odds } \\
\text { Ratio }\end{array}$ & $95 \% \mathrm{CI}$ & $p$-value \\
\hline Constant & -2.304 & 1.028 & .100 & - & .025 \\
\hline \multicolumn{6}{|l|}{ Demographics } \\
\hline Age & .073 & .024 & 1.076 & [1.026-1.127] & $.002 *$ \\
\hline Gender & .208 & .172 & 1.231 & {$[.879-1.723]$} & .229 \\
\hline \multicolumn{6}{|l|}{ Psychosocial problems } \\
\hline Distress & .293 & .243 & 1.341 & {$[.832-2.160]$} & .254 \\
\hline Alcohol risk & -.021 & .196 & .979 & {$[.667-1.438]$} & .915 \\
\hline \multicolumn{6}{|l|}{ Attitude } \\
\hline Attitude disclosure & .383 & .077 & 1.466 & {$[1.260-1.705]$} & $<.001 *$ \\
\hline Attitude help-seeking & -.206 & .286 & .814 & {$[.464-1.426]$} & .471 \\
\hline \multicolumn{6}{|l|}{ Stigma } \\
\hline Perceived public stigma & -.267 & .240 & .766 & {$[.478-1.226]$} & .266 \\
\hline Personal stigma & -.053 & .195 & .948 & [.648-1.389] & .786 \\
\hline
\end{tabular}

\section{Discussion}

The present study investigated predictors of disclosure and helpseeking behavior among students, and the main aim was to determine whether stigma and students' attitudes towards disclosure and helpseeking behavior, controlled for distress and hazardous alcohol use, predicted actual disclosure and help seeking. Our study showed five main findings: (a) as expected, participants in our study were a distressed group with over $56 \%$ reporting high levels of distress and over 20\% reporting hazardous alcohol use; (b) overall, students experienced little stigma, and both perceived public and personal stigma did not significantly predict disclosure and help seeking; (c) although students showed a rather unfavorable attitude towards disclosure and help-seeking, and only a few actually disclosed or sought help, interestingly, students who reported mental health problems (i.e., both distress and hazardous alcohol use) showed the least favorable attitude to disclosure, but at the same time showed the most positive attitude toward help-seeking; (d) disclosure was significantly predicted by both attitude towards disclosure and attitude towards help-seeking behavior, indicating that a student is more likely to disclose when one has a favorable attitude to disclosure, and is less likely to disclose when the attitude toward help-seeking is low; and, (e) help-seeking was significantly predicted by a students' age and attitude towards disclosure: older students with higher intentions to disclose seek more help than other students.

The combination of high levels of distress and hazardous alcohol use in students in our study with low levels of disclosure and help- 

help-seeking

seeking is consistent with many previous studies as mentioned in the introduction. Our results also show consistency with a review by [16], in which students did not seem to have deep-rooted attitudes towards disclosure and help-seeking behavior. Our finding on stigma was unexpectedly the opposite of previous studies by [35] and [28], who found high levels of stigma among American student samples and reported that stigma was a significant predictor of disclosure and helpseeking among students. This may be explained by cultural differences between American and European students, as students' stigma beliefs and attitudes are affected by the culture of the societies to which they belong. However, later studies suggested that traditionally emphasized barriers such as stigma 'clearly are not the entire story' and that it is possible that stigma takes more subtle forms, like self-stigma within university, which asks for a closer look in future research $[16,19]$. More recent studies demonstrated that not stigma, but intention to seek help was the most influential predictor of the utilization of mental health services $[17,36]$. Although our results do not support this finding directly, they did point in the same direction: help-seeking was predicted by attitudes to disclose, which are preceded by intentions.

Perhaps our results could be explained by identified barriers for disclosure and help-seeking in the Health Belief Model (HBM), such as a lack of perceived need for help, which refers to the individual's subjective experience that there's a mental health concern $[8,21]$. When making decisions about disclosure and help-seeking, recognition of the problem is conditional. According to [6], the tendency to disclose and seek help is also associated with identity: more distressed students are more likely to identify themselves as someone with mental health problems, which in turn is associated with the tendency to disclose. As university students often experience first onset of mental health problems during university, many may be unaware that they have mental health problems that would benefit from counseling or treatment $[2,29]$ which makes it difficult to recognize symptoms and to identify oneself as a person with mental health problems. Research by [37] and [38] showed that individuals with higher levels of mental health literacy (e.g., ability to recognize symptoms and correctly attribute them to mental illness) are more likely to seek psychological help. This could explain why in the present study the number of students with distress was high, but their intention to disclose and seek help was not: they might have low levels of mental health literacy. Individuals with low levels of mental health literacy often believe that their problem is transitory [39].

Even if students indicate a need for help, they might still maintain negative attitudes towards help-seeking that holds them back from actual help-seeking [36]. For instance, there is growing evidence that points out that problematic alcohol use is a particularly severely stigmatized condition and that the threshold for help-seeking is high for problematic drinkers because of shame and negative connotations regarding addiction health care [40]. Furthermore, studies show that many students were unaware of services or insurance coverage, and that they experience skepticism about treatment effectiveness, which, according to the Health Belief Model, hinders their belief in benefits of changing their behaviors [28]. This may also be an explanation for our results on little disclosure and help-seeking. Another explanation is consistent with the HBM's belief of social barriers and stigma. Although students in the present study did not report high levels of stigma, it is possible that they experienced social difficulties, like not wanting to burden others or have anyone to talk to, or having concerns about negative effects on their academic records, as reported in previous research $[39,41]$. Such concerns could act as a significant barrier to help seeking, particularly if the student perceives faculty staff as being the only people within the university who they can seek help from regarding mental health problems.

Students with mental health problems seek help from nonprofessionals, particularly peers, more frequently than from professionals $[6,19,21]$. This could explain why our results showed little help seeking from professionals, were it not for the fact that students in the present study also showed low levels of disclosure within their inner circle. Indeed, significantly higher levels of help seeking were found among students with severe mental health problems. Research has indicated that individuals who conceal distressing information are more likely to have negative help-seeking attitudes and that significant others' expectations may influence students' attitudes toward, and sense of control about, accessing services [17].

What could explain the lack of disclosure of students towards their family and friends, even when they experience high levels of distress for which they do seek professional help? According to our results stigma does not seem to play a determinant role, so can this be the result of other social pressure? Recent reports show an increase in perceived performance pressure and silent loneliness among students $[42,43]$. Students experience high expectations to succeed, and go through great lengths to meet up to these expectations, which they do not experience from their own family infrequently. They feel ashamed and that they don't belong if they can't comply. It seems relevant to further look into the possibility that this contributes to students' withholding to disclose, even within their inner circle.

\section{Limitations}

Although this study shows valuable insights in attitudes towards disclosure and help-seeking behavior as predictors of actual disclosure and help seeking among students, our findings must be considered within the context of its limitations. With regard to the cross-sectional nature of this study, causality may run in both ways. For example, a negative attitude towards disclosure may inhibit help-seeking behavior, but at the same time, little help-seeking may lead to a negative attitude towards disclosure. Longitudinal studies are needed to investigate these possible causalities.

Although the screening instruments used in the present study are also indicative for being at risk for disorders, we can't confirm the presence of these disorders. This makes it more difficult to compare our results to those of other studies in which students with mental health disorders were specifically investigated. Because both groups appear to experience barriers towards disclosure and help seeking, future research could incorporate both effects of undiagnosed symptoms and disorders to gain more insights into the underlying processes.

Our results showed some help-seeking among students who did not report symptoms of distress or hazardous alcohol use according to our screeners. Therefore it seems likely that they experienced other problems that we did not investigate. The supported HBM model in the present study may need to be replicated in future studies with additional psychosocial problems.

This study was conducted among a sample of students at a university of applied sciences with a mainly white population, which may increase the potential for selection bias and therefore may affect the generalizability of the study results to more diverse university populations. However, the large size of our random sample contributed to the reliability of the study results. 


\section{Implications for practice}

The present study has important implications for enabling factors that contribute to disclosure and help seeking among students. It implies that new approaches to help-seeking interventions may be useful. Whereas interventions for increasing disclosure and helpseeking are currently mainly aimed at stigma reduction and screening and linkage programs, our results show that stigma and screening are not the entire story. Disclosure and seeking help for mental health challenges are health promoting competencies, and it seems that related attitudes and awareness of one's own mental health need more attention in university students to enhance these competencies. In order to promote disclosure and seeking help behaviors, we suggest to promote mental health literacy and to increase available resources for students and the awareness regarding these resources. Mental health literacy, by definition, encompasses the ability to differentiate a mental health condition from general stress, and knowledge and beliefs about risk factors and available professional help $[38,44]$. For example, the Teen Mental Health school-based mental health literacy intervention for adolescents showed promise regarding knowledge of mental health in a university student population [45]. Further, reducing social barriers such as performance pressure and silently feeling ashamed as one can't live up to experienced expectations seem important targets when improving students' disclosure and help-seeking behaviors.

By improving personal knowledge about mental health problems and related attitudes and behaviors, education-based programs, like Teen Mental Health, could increase the likelihood of disclosure and help-seeking behaviors among university students [14]. To promote students' engagement in mental health literacy programs, the use of expert peers by experience is advised, as well as making mental health literacy part of the curriculum. In order to break down social barriers, universities should invest in an open, supportive study environment, in which seeking help is seen as normal, which would suit the experience of many students that university is a challenging time.

\section{Conclusions}

Although psychosocial problems seem highly prevalent among students, there is little intention to disclose or seek help for dealing with these issues. Perhaps surprisingly, both perceived public and personal stigma were not found to be significant barriers for disclosure and help seeking. Not only did students experienced little stigma, it also did not predict disclosure or help-seeking. Although the results showed that students showed not very positive attitudes toward help-seeking, but these attitudes did predict actual disclosure and help-seeking behavior. Many universities have adopted stigma-reduction campaigns to facilitate treatment use, but our results call attention for the need for additional interventions aimed at attitudes towards disclosure and help-seeking and awareness of one's own mental health, like the enhancement of mental health literacy. Educating students about mental health issues and available mental health services may increase the likelihood of disclosure and help-seeking behaviors.

\section{Acknowledgement}

We would like to thank all students and employees of Windesheim University of Applied Sciences who made a contribution to this study and who supported the development of the web-based questionnaires. We also like to thank Arjan Bos at the Open University, the Netherlands, for making the Mental Illness Disclosure Scale available for us to use and for his consultation. We also like to thank Mariëlle ZondervanZwijnenburg for her consultation on the statistical analyses.

\section{Statement of ethics}

The Executive Board of Windesheim University of Applied Sciences granted approval for the Study environment, Health and Study Success survey. All subjects received written information about the aim of the study and participants participated voluntarily. The consent of the participants was obtained by virtue of survey completion. All data were analyzed anonymously. The authors have no ethical conflicts to disclose.

\section{Disclosure statement}

The authors have no conflicts of interest to declare.

\section{Funding}

This work was supported by the Netherlands Organization for Scientific Research (NWO) under grant number 023.004.118.

\section{Author contributions}

All authors were responsible for the study design. Jolien $\mathrm{M}$. Dopmeijer collected the data. Jolien M. Dopmeijer and Jannet M. de Jonge were responsible for the statistical analyses and for the interpretation of the data in agreement with all authors. Jolien M. Dopmeijer wrote the first version of the manuscript and all authors participated in the revisions of the manuscript. All authors read and approved the final manuscript.

\section{References}

1. Tosevski DL, Milovancevic MP, Gajic SD (2010) Personality and psychopathology of university students. Curr Opin Psychiatry, 23: 48-52. [Crossref]

2. Kessler Ronald C, Berglund P, Demler O, Jin R, Merikangas KR, et al. (2005) Lifetime prevalence and age-of-onset distributions of DSM-IV disorders in the national comorbidity survey replication. Arch Gen Psychiatry 62: 593-602. [Crossref]

3. McLafferty M, Lapsley CR, Ennis E, Armour C, Murphy S, et al. (2017) Mental health, behavioural problems and treatment seeking among students commencing university in Northern Ireland. PLoS One 12: 1-15. [Crossref]

4. Stolker BE, Lafreniere KD (2012) The Influence of Perceived Stress, Loneliness, and Learning Burnout on University Students' Educational Experience. College Student Journal 49: 146-159.

5. Auerbach RP, Alonso J, Axinn WG, Cuijpers P, Ebert DD, et al. (2016) Menta disorders among college students in the World Health Organization World Mental Health Surveys. Psychol Med 46: 2955-2970. [Crossref]

6. Corrigan PW, Kosyluk KA, Markowitz F, Brown RL, Conlon B, et al. (2016) Menta illness stigma and disclosure in college students. J Ment Health 25: 224-230. [Crossref]

7. Dyrbye LN, Thomas MR, Massie FS, Power DV, Eacker A, et al. (2008) Burnout and suicidal ideation among U.S. medical students. Ann Intern Med 149: 334-341. [Crossref]

8. Hunt J, Eisenberg D (2010) Mental Health Problems and Help-Seeking Behavior Among College Students. J Adolesc Health 46: 3-10. [Crossref]

9. Ishak W, Nikravesh R, Lederer S, Perry R, Ogunyemi D, et al. (2013) Burnout in medical students: A systematic review. Clinical Teacher 10: 242-245.

10. Newcomb-Anjo SE, Villemaire-Krajden R, Takefman K, Barker ET (2017) The Unique Associations of Academic Experiences With Depressive Symptoms in Emerging Adulthood. Emerging Adulthood 5: 75-80.

11. Reyes MES, Davis RD, San Diego CA, Tamayo MCA, Dela Cruz NVV, et al. (2016) Exploring five factor model personality traits as predictors of burnout dimensions among college students in the Philippines. Journal of Tropical Psychology 6: e4.

12. Verhoog S, Dopmeijer JM, De Jonge JM, Van Der Heijde CM, Vonk P, et al. (2019) The Use of the Alcohol Use Disorders Identification Test - Consumption as an Indicator of Hazardous Alcohol Use among University Students. Eur Addict Res 26: 1-9. [Crossref]

13. Zivin K, Eisenberg D, Gollust SE, Golberstein E (2009) Persistence of mental health problems and needs in a college student population. J Affect Disord 117: 180-185. [Crossref] 
Dopmeijer JM (2020) Predicting disclosure and help-seeking in university students with psychosocial problems based on stigma and attitudes towards disclosure and help-seeking

14. Sontag-padilla L, Dunbar M, Ye F, Mph CK, Mph RF, et al. (2018) Strengthening College Students' Mental Health Knowledge, Awareness, and Helping Behaviors: The\&nbsp; Impact of Active Minds, a Peer Mental Health Organization. J Am Acad Child Adolesc Psychiatry 57: 1-8. [Crossref]

15. Sontag-Padilla L, Woodbridge MW, Mendelsohn J, D'Amico EJ, Osilla KC, et al. (2016) Factors affecting mental health service utilization among California public college and university students. Psychiatr Serv 67: 890-897. [Crossref]

16. Eisenberg, Daniel, Hunt J, Speer N (2013) Mental health in american colleges and universities: Variation across student subgroups and across campuses. J Nerv Ment Dis 201: 60-67. [Crossref]

17. Li W, Denson LA, Dorstyn DS (2018) Understanding Australian university students' mental health help-seeking: An empirical and theoretical investigation. Aust J Psychol 70: $30-40$.

18. Rosenstock IM (1966) Why people use health services. Milbank $Q$ p: 83. [Crossref]

19. Eisenberg, Daniel, Hunt J, Speer N (2012) Help seeking for mental health on college campuses: Review of evidence and next steps for research and practice. Harv Rev Psychiatry 20: 222-232. [Crossref]

20. Corrigan P (2004) How stigma interferes with mental health care. Am Psychol 59: 614625. [Crossref]

21. Romanson EEJ (2018) Online help seeking in emerging adults: The role of attachment style, emotion regulation, and distress disclosure. Dissertation Abstracts International: Section B: The Sciences and Engineering.

22. Crone EA, Dahl RE (2012) Understanding adolescence as a period of social-affective engagement and goal flexibility. Nat Rev Neurosci 13: 636-650. [Crossref]

23. Erikson E (1968) Youth: Identity and Crisis. New York, NY: WW.

24. Bos AER, Kanner D, Muris P, Janssen B, Mayer B (2009) Mental illness stigma and disclosure: Consequences of coming out of the closet. Issues Ment Health Nurs 30 509-513. [Crossref]

25. Kessler RC, Andrews G, Colpe LJ, Hiripi E, Mroczek DK, (2002) Short screening scales to monitor population prevalences and trends in non-specific psychological distress. Psychol Med 32: 959-976. [Crossref]

26. Bush K, Kivlahan D, McDonell M, Fihn S, Bradley K (1998) The AUDIT alcohol consumption questions (AUDIT-C): an effective brief screening test for problem drinking. Ambulatory Care Quality Improvement Project (ACQUIP). Alcohol Use Disorders Identification Test. Arch Intern Med 158: 1789-1795. [Crossref]

27. Mackenzie CS, Knox VJ, Gekoski WL, Macaulay HL (2004) An Adaptation and Extension of the Attitudes Toward Seeking Professional Psychological Help Scale1. J Appl Soc Psychol 34: 2410-2433.

28. Eisenberg D, Downs MF, Golberstein E, Zivin K (2009) Stigma and Help Seeking for Mental Health Among College Students. Med Care Res Rev pp. 522-541.[Crossref]
29. Link BG (1987) Understanding Labeling Effects in the Area of Mental Disorders: An Assessment of the Effects of Expectations of Rejection. Am Sociol Rev 52: 96-112.

30. Link BG, Cullen FT, Struening E, Shrout PE, Dohrenwend BP (1989) A Modified Labeling Theory Approach to Mental Disorders: An Empirical Assessment. Am Sociol Rev 54: 400-423.

31. IBM (2017) IBM SPSS Statistics Software for Windows, Version 25.

32. Lin FJ (2008) Solving multicollinearity in the process of fitting regression model using the nested estimate procedure. Quality and Quantity 42: 417-426.

33. Pheko MM, Chilisa R, Balogun SK, Kgathi C (2013) Predicting intentions to seek Psychological Help among Botswana University students: The role of Stigma and Help-Seeking attitudes. SAGE Open 3: 1-11.

34. Huberty CJ, Morris JD (1989) Multivariate Analysis Versus Multiple Univariate Analyses. Psychol Bull 105: 302-308.

35. Golberstein E, Eisenberg D, Gollust SE (2008) Perceived stigma and mental health care seeking. Psychiatr Serv 59: 392-399.

36. Li W, Dorstyn DS, Denson LA (2016) Predictors of mental health service use by young adults: A systematic review. Psychiatr Serv 67: 946-956. [Crossref]

37. Coles ME, Coleman SL (2010) Barriers to treatment seeking for anxiety disorders Initial data on the role of mental health literacy. Depress Anxiety 27: 63-71. [Crossref]

38. Cheng HL, Wang C, McDermott RC, Kridel M, Rislin JL (2018) Self-Stigma, Mental Health Literacy, and Attitudes Toward Seeking Psychological Help. J Couns Dev 96 : 64-74.

39. Downs MF, Eisenberg D (2012) Help seeking and treatment use among suicidal college students. J Am Coll Health 60: 104-114.

40. Schomerus G, Lucht M, Holzinger A, Matschinger H, Carta MG, et al. (2011) The stigma of alcohol dependence compared with other mental disorders: A review of population studies. Alcohol Alcohol 46: 105-112. [Crossref]

41. Chew-Graham CA, Rogers A, Yassin N (2003) "I wouldn't want it on my CV or their records": Medical students' experiences of help-seeking for mental health problems. Med Educ 37: 873-880. [Crossref]

42. The Council for Public Health and Society (2018) About concerned.

43. RIVM (2017) Trend scenario VTV-2018 identifies social challenges for the future.

44. Jorm AF, Korten AE, Jacomb PA, Christensen H, Rodgers B (1997) "Mental health literacy": A survey of the public's ability to recognise mental disorders and their beliefs about the effectiveness of treatment. Med J Aust 166: 182-186. [Crossref]

45. Milin R, Kutcher S, Lewis SP, Walker S, Wei Y, et al. (2016) Impact of a Mental Health Curriculum on Knowledge and Stigma among High School Students: A Randomized Controlled Trial. J Am Acad Child Adolesc Psychiatry 55: 383-391.

Copyright: (C2020 Dopmeijer JM. This is an open-access article distributed under the terms of the Creative Commons Attribution License, which permits unrestricted use, distribution, and reproduction in any medium, provided the original author and source are credited. 